\section{$\underset{\substack{\text { hommes } \\ \text { \& migrations }}}{ }$}

\section{Hommes \& migrations}

Revue française de référence sur les dynamiques

migratoires

$1300 \mid 2012$

Nouveaux modèles migratoires en Méditerranée

\title{
Fouad Laroui, La Vieille Dame du riad
}

Pocket, 2012, 224 pages, 6,10 euros

\section{Mustapha Harzoune}

\section{Q OpenEdition}

1 Journals

\section{Édition électronique}

URL : http://journals.openedition.org/hommesmigrations/961

DOI : 10.4000/hommesmigrations.961

ISSN : 2262-3353

\section{Éditeur}

Musée national de l'histoire de l'immigration

\section{Édition imprimée}

Date de publication : 1 novembre 2012

Pagination : 165-166

ISSN : 1142-852X

\section{Référence électronique}

Mustapha Harzoune, «Fouad Laroui, La Vieille Dame du riad», Hommes \& migrations [En ligne], $1300 \mid$ 2012, mis en ligne le 29 mai 2013, consulté le 22 septembre 2020. URL : http:// journals.openedition.org/hommesmigrations/961 ; DOI : https://doi.org/10.4000/hommesmigrations. 961

Ce document a été généré automatiquement le 22 septembre 2020.

Tous droits réservés 


\title{
Fouad Laroui, La Vieille Dame du riad
}

\author{
Pocket, 2012, 224 pages, 6,10 euros
}

\section{Mustapha Harzoune}

\section{RÉFÉRENCE}

Fouad Laroui, La Vieille Dame du riad, Pocket, 2012, 224 pages, 6,10 euros

1 Marocain et batave d'adoption, Fouad Laroui est ingénieur de formation, docteur en sciences économiques, installé à Amsterdam où, après y avoir enseigné l'économétrie puis les sciences de l'environnement, il professe aujourd'hui la littérature. Son premier roman, Les Dents du topographe (Julliard, 1996) lui valut le Prix découverte Albert Camus. Deux ans plus tard, il reçoit le prix Méditerranée des lycées et le prix Beur FM pour De quel amour blessé (Julliard). Auteur prolixe, son sixième roman Une année chez les Français (Julliard, 2010) est retenu parmi la première sélection du prix Goncourt et La Vieille Dame du riad (Julliard, 2011) vient d'être réédité en poche. Il est aussi l'auteur de nombreux recueils de nouvelles et de chroniques dont Des Bédouins dans le polder. Histoires tragi-comiques de l'émigration (Zellige, 2010) ou Le jour où j'ai déjeuné avec le Diable (Zellige, 2011).

Dans Le Drame linguistique marocain paru au Maroc chez Le Fennec en 2010, Fouad Laroui livre une longue réflexion, nourrie de données linguistiques, syntaxiques, sociologiques et littéraires, pour interroger le statut des langues au Maroc. L'analyse est transposable à nombre de pays de cette vaste sphère dite "arabe" mais qui recouvre une diversité culturelle et linguistique par trop négligée voire ignorée - à commencer par le voisin algérien. Le "drame linguistique", au cœur des interrogations identitaires, a pour nom la "diglossie" entre langue savante et langue(s) populaire(s). La première est formée de l'arabe classique, celui du Coran et de l'arabe moderne, celui des médias, des discours politiques et autres feuilletons télévisés. Quant à la seconde, l'arabe parlé ou darija, elle est le lot commun de tout un chacun : paysan du cru ou citadin, tchitchi des beaux quartiers ou lumpen des bas-fonds, papicha romantique ou intellectuelle féministe, voilée ou laïcarde convaincue, recalé du système scolaire ou diplômé du 
supérieur... L'arabe classique ou moderne, celui des écoles, n'est la langue maternelle de personne. Quant à la langue parlée par les peuples, nulle part elle est enseignée ! Si, comme le dit l'auteur, l'arabe classique est une langue étrangère au Maroc, qu'en est-il de son statut de langue "nationale" quand, dans le même mouvement, la langue (ou les langues) parlée(s) par la nation est (sont) niée(s) ? Ne serait-ce pas une autre forme de colonialisme? Car les deux langues sont différentes: la darija marocaine serait, du moins dans sa syntaxe, davantage influencée par le berbère que par l'arabe classique. L'Égyptien Chérif Choubachy parle même d'un "abîme" entre langue classique et langue parlée. Pour ce qui est du berbère, les choses sont claires : "Je suis berbère. L'arabe est pour moi une langue aussi étrangère que le français", dixit l'écrivain Moha Souag.

Dans cet embrouillamini linguistique, écrire en langue française n'est pas un choix mais une échappatoire, une façon de sortir du conflit en utilisant la seule langue à disposition, l'arabe classique étant réservé à quelques rares lettrés et la darija étant la grande absente des livres et cahiers d'écolier. Fouad Laroui invoque une fois de plus la notion de "malédiction", appliquée cette fois à l'écrivain quant à sa relation à la langue d'écriture. Comment traduire ses émotions, sa personnalité, sa sensibilité, sa chair, ce qu'il a emmagasiné dans son enfance, à travers les mots et ici les mots de sa mère ? Qu'en est-il de l'identité, si la langue qui en constitue le substrat essentiel n'est pas enseignée, ne permet pas de s'exprimer et de dire son imaginaire? Pour l'auteur, la naissance de la littérature d'expression française est la conséquence de cette diglossie, une réponse à la schizophrénie.

4 Pour sortir de cette situation aux conséquences culturelles, éducatives, individuelles et collectives alarmantes, il faudrait rendre toute sa place, tout son "prestige", à la darija, non seulement en l'enseignant mais aussi en abandonnant (par souci notamment de classification et de nomenclature) la graphie arabe pour l'écriture latine, à la façon d'un Atatürk. Scandale? Provocation? Sacrilège même (car il ne faut pas oublier que la langue arabe est la langue du Coran...) ? Pourtant, là aussi, la société semble innover et notamment... les publicitaires qui y vont de leurs slogans en darija écrits en lettres latines. Sont-ils plus au fait des ressorts souterrains des sociétés? des dynamiques culturelles à l'œuvre? des attentes du citoyen, à tout le moins du consommateur?

En tout cas, dans La Vieille Dame du riad où un couple de Français découvre qu'une vieille femme, sortie du fond des âges, se cache dans le riad qu'ils viennent d'acquérir à Marrakech, Fouad Laroui applique sa recette linguistique. Il fait, avec élégance et humour, flirter la langue française et le dialectal marocain, offrant au lecteur la possibilité d'entrer un peu plus en "connivence" (François Jullien) avec l'univers culturel et linguistique marocain. 